Article

\title{
Lignin Synthesis, Affected by Sucrose in Lotus (Nelumbo nucifera) Seedlings, Was Involved in Regulation of Root Formation in the Arabidopsis thanliana
}

\author{
Libao Cheng ${ }^{1, *}$, Chen Zhao ${ }^{1}$, Minrong Zhao ${ }^{1}$, Yuyan Han ${ }^{1}$ and Shuyan Li $^{2}$ \\ 1 School of Horticulture and Plant Protection, Yangzhou University, Yangzhou 225009, China; \\ zhaochen2878359757@163.com (C.Z.); wayzyj@163.com (M.Z.); Hyyluckystar@163.com (Y.H.) \\ 2 College of Guangling, Yangzhou University, Yangzhou 225009, China; lsydbnd@163.com \\ * Correspondence: lbcheng@yzu.edu.cn
}

check for

updates

Citation: Cheng, L.; Zhao, C.; Zhao,

M.; Han, Y.; Li, S. Lignin Synthesis,

Affected by Sucrose in Lotus

(Nelumbo nucifera) Seedlings, Was

Involved in Regulation of Root

Formation in the Arabidopsis thanliana.

Int. J. Mol. Sci. 2022, 23, 2250 .

https://doi.org/10.3390/

ijms23042250

Academic Editor: Esther M.

González

Received: 19 January 2022

Accepted: 15 February 2022

Published: 18 February 2022

Publisher's Note: MDPI stays neutral with regard to jurisdictional claims in published maps and institutional affiliations.

Copyright: (C) 2022 by the authors. Licensee MDPI, Basel, Switzerland. This article is an open access article distributed under the terms and conditions of the Creative Commons Attribution (CC BY) license (https:// creativecommons.org/licenses/by/ $4.0 /)$

\begin{abstract}
Adventitious roots (ARs) have an unmatched status in plant growth and metabolism due to the degeneration of primary roots in lotuses. In the present study, we sought to assess the effect of sucrose on ARs formation and observed that lignin synthesis was involved in ARs development. We found that the lignification degree of the ARs primordium was weaker in plants treated with $20 \mathrm{~g} / \mathrm{L}$ sucrose than in $50 \mathrm{~g} / \mathrm{L}$ sucrose treatment and control plants. The contents of lignin were lower in plants treated with $20 \mathrm{~g} / \mathrm{L}$ sucrose and higher in plants treated with $50 \mathrm{~g} / \mathrm{L}$ sucrose. The precursors of monomer lignin, including p-coumaric acid, caffeate, sinapinal aldehyde, and ferulic acid, were lower in the GL50 library than in the GL20 library. Further analysis revealed that the gene expression of these four metabolites had no novel difference in the GL50/GL20 libraries. However, a laccase17 gene (NnLAC17), involved in polymer lignin synthesis, had a higher expression in the GL50 library than in the GL20 library. Therefore, NnLAC17 was cloned and the overexpression of NnLAC17 was found to directly result in a decrease in the root number in transgenic Arabidopsis plants. These findings suggest that lignin synthesis is probably involved in ARs formation in lotus seedlings.
\end{abstract}

Keywords: lotus; adventitious roots; lignin; sucrose; NnLAC17

\section{Introduction}

The lotus is an aquatic plant that contains multiple nutrients. The lotus is believed to be an important vegetable and is wildly cultivated in the Yangtze River and Yellow River basins owing to the suitable climate [1,2]. Adventitious roots (ARs) are secondary roots that play an important role in the water and nutrient uptake in plants, especially in lotuses, which have underdeveloped principal roots. ARs are always located on the hypocotyl of seedlings in lotuses, and approximately two weeks are required for AR emergence [3]. There are three developmental stages in the entire period of AR formation [4,5]: the first stage is the induced period, where the normal cell is divided and developed into meristematic cells; the second stage is the development stage, where the root primordium is formed from meristematic cells [6]; and the third stage is where the root primordium emerges from the epidermis of the stem or leaf $[7,8]$. The signaling transduction pathway of plant hormones is found to be involved in various metabolic processes of plant growth In the past years, indole-3-acetic acid (IAA) has been reported to play an important role in root formation at the inducted, developmental, and emergence stages $[9,10]$. At the same time, ethylene is another important factor to regulate ARs formation, and the role of ethylene in AR formation is mainly carried out at the induction stage [11-13]. IAA and ethylene can also cooperatively regulate AR development. The metabolism and sensitivity of auxin are affected by ethylene. However, the role of ethylene is also regulated by IAA [14-16]. Sugar is involved in root development [17]. In fact, the role of sucrose in the regulation of root formation has been revealed to be similar to that of some types of 
plant hormones. Further, sucrose can promote the formation of root primordium and late development $[10,18]$. In lotuses, it is found that there is an interaction between sucrose and IAA during AR formation. The exogenous application of sucrose can affect the IAA content, and exogenous IAA reversely changes the endogenous sucrose content during AR formation [19]. Lignin is an important component of cells during plant growth and metabolism [20]. Normally, lignin, which is a polyphenolic polymer, contains three types of monomers, namely the S-type, H-type, and G-type [21]. According to recently reported data, a close relationship exists between lignin metabolism and AR formation. Cho et al. [22] reveal that indolebutyric acid (IBA) treatment promotes root primordial development, but suppresses lignin synthesis. Peroxidase genes are responsible for lignin synthesis, and this peroxidase gene expression is found to be upregulated after IBA treatment $[23,24]$. Moreover, two different types of Ebenus cretica (rooting and non-rooting genotypes) are found to have different lignin and peroxidase activities [25]. In sweet potato, the formation of the storage root is reduced and vascular lignification is promoted after the exogenous application of plant hormones [26]. A high expression of genes related to lignin synthesis occurs in wild species (not from storage roots) relative to cultivated species [27]. In mung bean seedlings, the genes responsible for lignin biosynthesis are down-regulated after IBA treatment, which significantly promotes AR formation [28]. The development of rice roots is previously found to be inhibited, whereas lignin deposition is increased in cell walls under conditions of stress [29].

Sucrose is an important signal molecular that is involved in various biological process in plant. In the present study, we found that sucrose was involved in the lignin synthesis of lotus seedlings, and the lignin content, which was regulated by NnLAC17, affected root formation based on the changes in physiological and biochemical indexes, microstructure observation, RNA-seq (RNA-sequencing) technique, and transgenic plant analysis. This finding provided evidence that ARs formation is regulated by multiple factors, and, at the same time, it also gave new insight on the possible regulatory network of the ARs formation of lotus seedlings.

\section{Results}

\subsection{Effect of Sucrose on AR Formation}

It was shown that seedlings treated with $20 \mathrm{~g} / \mathrm{L}$ sucrose had a higher number of ARs than that of control plants after transferal to water. Such findings indicated that $20 \mathrm{~g} / \mathrm{L}$ sucrose significantly promoted the formation of ARs. The developmental process of ARs was markedly delayed in seedlings treated with $50 \mathrm{~g} / \mathrm{L}$ sucrose. In fact, the seedlings cultured on the MS culture medium containing $20 \%$ sucrose had a more adventitious root number than that of $50 \%$ sucrose (Figure 1a). Further analysis revealed that the number of ARs was lower in plants treated with $50 \mathrm{~g} / \mathrm{L}$ sucrose than in control plants and $20 \mathrm{~g} / \mathrm{L}$ sucrose treatment (Figure 1b). In summary, we concluded that low concentrations of sucrose accelerated ARs formation, whereas high concentrations inhibited this process.

\subsection{Observation of the Paraffin Sections}

The microstructure of hypocotyls was analyzed for ARs development following treatment with $20 \mathrm{mg} / \mathrm{L}$ and $50 \mathrm{mg} / \mathrm{L}$ sucrose. The primordia of ARs were formed around the stomata in the hypocotyl. The induction and development of ARs took approximately 2 days after treatment with $20 \mathrm{~g} / \mathrm{L}$ sucrose; however, a longer time was taken by treatment with $50 \mathrm{~g} / \mathrm{L}$ sucrose. In the last stage (expressed stage) of ARs development, a greater number of ARs broke through the epidermis of hypocotyl following treatment with $20 \mathrm{mg} / \mathrm{L}$ sucrose than that of CK and the treatment with $50 \mathrm{~g} / \mathrm{L}$ sucrose. Crystal violet staining was used to monitor the acclimation of lignin. Different degrees of staining were observed after treatment with 0 sucrose, $20 \mathrm{~g} / \mathrm{L}$, and $50 \mathrm{~g} / \mathrm{L}$ sucrose during AR development. A more intense crystal violet staining was observed after treatment with $50 \mathrm{~g} / \mathrm{L}$ sucrose than CK and the treatment with $20 \mathrm{~g} / \mathrm{L}$ sucrose, which indicated that the accumulation of lignin was higher through treatment with $50 \mathrm{~g} / \mathrm{L}$ sucrose than CK and $20 \mathrm{~g} / \mathrm{L}$ sucrose treatment. 
Further, the lowest content of lignin was observed within $6 \mathrm{~d}$ of treatment with $20 \mathrm{~g} / \mathrm{L}$ sucrose (Figure 2).
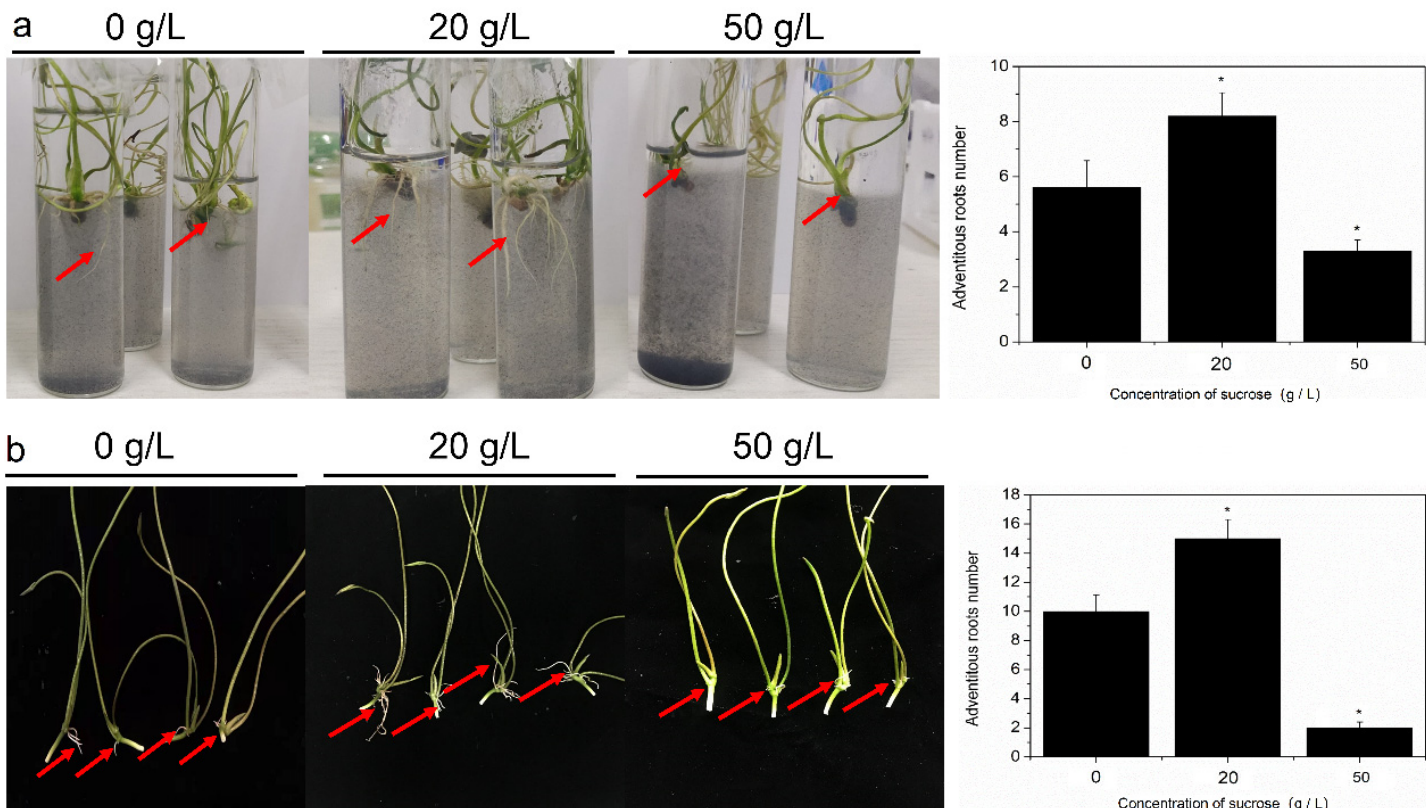

Figure 1. The influence of $20 \mathrm{~g} / \mathrm{L}$ and $50 \mathrm{~g} / \mathrm{L}$ sucrose on ARs formation in lotus seedlings. (a) AR formation in the water; (b) AR development in the MS medium (the data of (b) were referred by Cheng et al. 2020 [19]). (Red arrow represents point of the growth of adventitious root; "*” represents significant difference, $p<0.05$.)
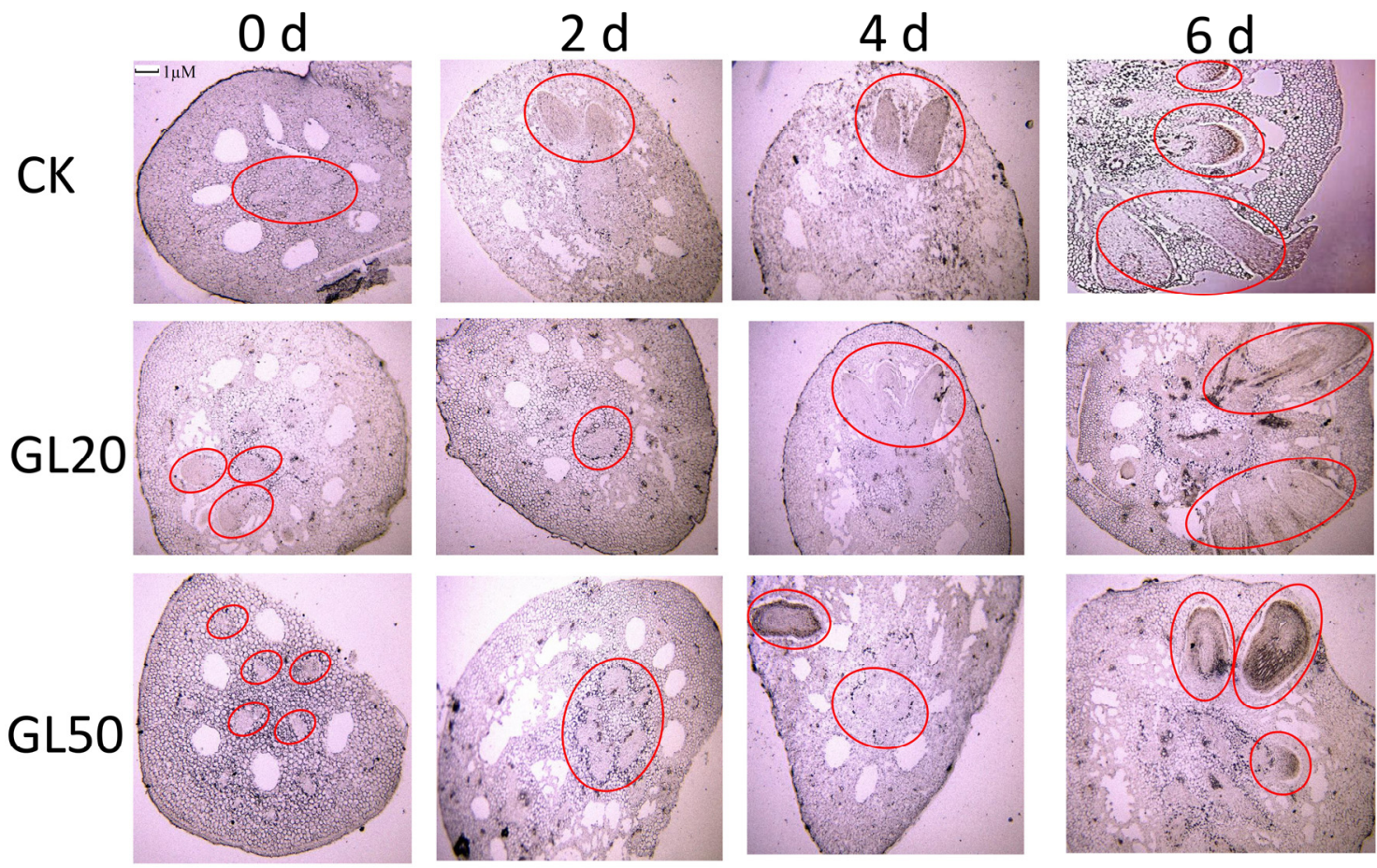

Figure 2. The change in lignin synthesis based on an observation of the microstructure during AR formation in lotus seedlings treated with $20 \mathrm{~g} / \mathrm{L}$ and $50 \mathrm{~g} / \mathrm{L}$ sucrose. GL20 represents $20 \mathrm{~g} / \mathrm{L}$ treatment and GL50 represents $50 \mathrm{~g} / \mathrm{L}$ treatment. The seedlings were firstly treated with $20 \mathrm{~g} / \mathrm{L}$ and $50 \mathrm{~g} / \mathrm{L}$ sucrose, and then transferred into water for continue growth. The hypocotyls at 0 days, 2 days, 4 days, and 6 days after transfer were collected for microstructure observation. 


\subsection{Determination of Monomer Lignin and Polymer Lignin Contents}

The seedlings were treated with $20 \mathrm{mg} / \mathrm{L}$ and $50 \mathrm{mg} / \mathrm{L}$ sucrose for two days, and the contents of monomer lignin and polymer lignin were determined for the CK0, CK1, GL20, and GL50 libraries (Figure 3a). The seedlings' monomer lignin was found to be composed of two types of lignin ( $G$ and $S$ types), whereas it did not contain the H type. Of the two types of lignin, the content of the G-type lignin was greater than that of the S-type lignin. The lignin content of the $G$ and $S$ types was significantly higher at CK1 than CK0. Seedlings treated with $50 \mathrm{~g} / \mathrm{L}$ sucrose had a higher lignin content than at CK0, whereas a remarkable decrease was observed after treatment with $20 \mathrm{~g} / \mathrm{L}$ sucrose (Figure 3b). Further analysis revealed that more than 60\% lignin was G-type lignin, and less than $40 \%$ lignin was S-type lignin at CK0 and CK1 (20 g/L and $50 \mathrm{~g} / \mathrm{L}$ sucrose treatment) (Figure 3c). The content of polymer lignin was also determined following the above treatments. The content of polymer lignin was found to increase at CK1 with $50 \mathrm{~g} / \mathrm{L}$ sucrose and CK0. Further, more content was found at CK1 and $50 \mathrm{~g} / \mathrm{L}$ sucrose than at CK0. However, the total lignin was significantly decreased after treatment with $20 \mathrm{~g} / \mathrm{L}$ sucrose (Figure 3d).

a

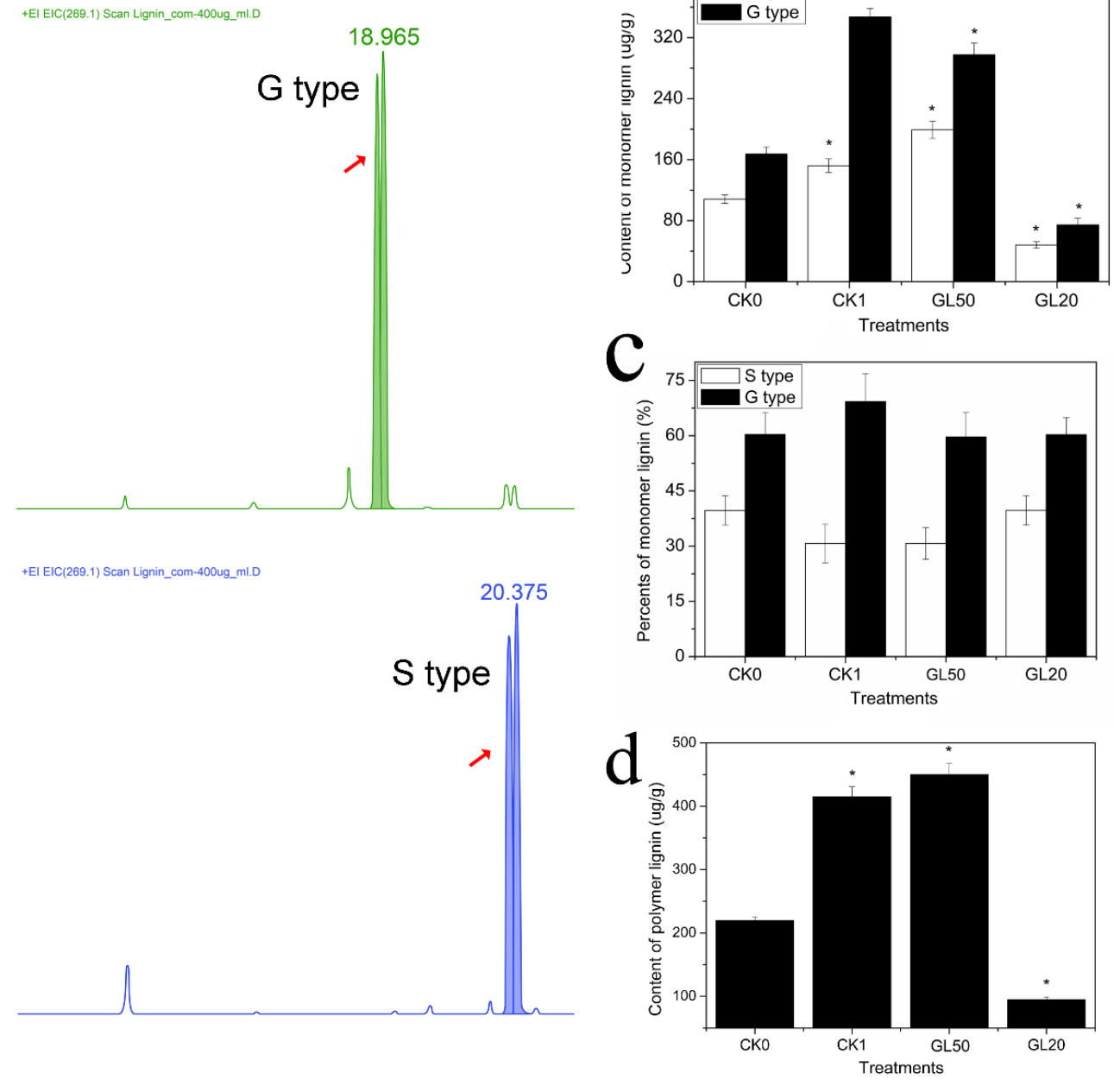

Figure 3. Identification of the lignin content in lotus seedlings treated with $20 \mathrm{~g} / \mathrm{L}$ and $50 \mathrm{~g} / \mathrm{L}$ sucrose during ARs formation. (a) The lignin was analyzed by ESI-QTRAP-MS/MS (Electrospray Ionization Quadrupole Ion TRAP Mass Spectrum/Mass Spectrum). (b) Determination of the monomer lignin content in the CK0, CK1, GL50, and GL20 libraries. (c) Determination of the monomer lignin types in the CK0, CK1, GL50, and GL20 libraries. (d) Analysis of polymer lignin content in the CK0, CK1, GL50, and GL20 libraries. (Red arrow represents acquisition time of G-type and S-type lignin, “*” represents significant difference at 0.05 level, $p<0.05$.) 


\subsection{The Change in Metabolites Related to Lignin Biosynthesis Owing to Sucrose Treatment}

Four libraries, namely CK0, CK1, GL20, and GL50, were constructed to monitor the change in 14 metabolites (p-coumaric acid, p-coumaraldehyde, sinapic acid, sinapyl alcohol, p-coumaryl alcohol, caffeyl alcohol, caffeyl aldehyde, sinapinaldehyde, L-phenylalanine, coniferyl alcohol, caffeate, ferulic acid, 4-hydroxy-3-methoxycinnamaldehyde, and cinnamic acid), which were involved in the synthesis of monomer lignin in lotus seedlings treated with different concentrations of sucrose. Seven metabolites, including sinapinaldehyde and 4-hydroxy-3-methoxycinnamaldehyde, were involved in S-lignin synthesis; coniferyl alcohol, caffeate, and ferulic acid were involved in G-lignin and S-lignin synthesis; L-phenylalanine and cinnamic acid were the primary products for G-lignin and S-lignin synthesis; and six metabolites, such as sinapinaldehyde, 4-hydroxy-3-methoxycinnamaldehyde, coniferyl alcohol, ferulic acid, cinnamic acid, and L-phenylalanine were, were found to increase, and only p-coumaric acid decreased in the CK1/CK0, GL20/CK0, and GL50/CK0 libraries, respectively. Based on the data obtained from these libraries, we further analyzed the altered metabolites in the GL50/GL20 libraries. The content of four important metabolites, namely p-coumaric acid, caffeate, sinapinal aldehyde, and ferulic acid, were found to significantly decrease (Table 1 ).

Table 1. Analysis of the metabolism of monomer lignin in lotus seedlings treated with $20 \mathrm{~g} / \mathrm{L}$ and $50 \mathrm{~g} / \mathrm{L}$ sucrose (NA means that the metabolites are too little to be determined; " " represents no difference between two libraries).

\begin{tabular}{|c|c|c|c|}
\hline Compounds & $p$ Value & $\begin{array}{c}\text { Fold } \\
\text { Change }\end{array}$ & Types \\
\hline \multicolumn{4}{|c|}{ CK1/CK0 libraries } \\
\hline p-Coumaric acid & 0.0112 & 0.2743 & Down-regulated \\
\hline p-Coumaraldehyde & NA & NA & \\
\hline Sinapic acid & NA & NA & \\
\hline Sinapyl alcohol & NA & NA & \\
\hline p-Coumaryl alcohol & NA & NA & \\
\hline Caffeyl alcohol & NA & NA & \\
\hline Caffeyl aldehyde & NA & NA & \\
\hline Sinapinaldehyde & 0.0015 & 3.4747 & Up-regulated \\
\hline L-Phenylalanine & 0.0052 & 1.8344 & Up-regulated \\
\hline Coniferyl alcohol & 0.0225 & 23.0678 & Up-regulated \\
\hline Caffeate & 0.0305 & 1.4309 & Up-regulated \\
\hline Ferulic acid & 0.0564 & 1.6682 & Up-regulated \\
\hline 4-Hydroxy-3-methoxycinnamaldehyde & 0.0019 & 10.5479 & Up-regulated \\
\hline Cinnamic acid & 0.0036 & 2.5194 & Up-regulated \\
\hline \multicolumn{4}{|c|}{ GL20/CK0 } \\
\hline p-Coumaric acid & 0.0407 & 0.1107 & Down-regulated \\
\hline p-Coumaraldehyde & NA & NA & \\
\hline Sinapic acid & NA & NA & \\
\hline Caffeate & 0.0369 & 1.156 & \\
\hline Sinapyl alcohol & NA & NA & \\
\hline p-Coumaryl alcohol & NA & NA & \\
\hline
\end{tabular}


Table 1. Cont.

\begin{tabular}{|c|c|c|c|}
\hline Compounds & $p$ Value & $\begin{array}{c}\text { Fold } \\
\text { Change }\end{array}$ & Types \\
\hline Caffeyl alcohol & NA & NA & \\
\hline Caffeyl aldehyde & NA & NA & \\
\hline Sinapinal dehyde & 0.0147 & 7.2121 & Up-regulated \\
\hline L-Phenylalanine & 0.0497 & 1.6486 & Up-regulated \\
\hline Coniferyl alcohol & 0.01762 & 19.5263 & Up-regulated \\
\hline Ferulic acid & 0.0113 & 2.3898 & Up-regulated \\
\hline 4-Hydroxy-3-methoxycinnamaldehyde & 0.0415 & 16.7289 & Up-regulated \\
\hline Cinnamic acid & 0.02470 & 2.1252 & Up-regulated \\
\hline \multicolumn{4}{|l|}{ GL50/CK0 } \\
\hline p-Coumaric acid & 0.04766 & 0.079 & Down-regulated \\
\hline p-Coumaraldehyde & NA & NA & \\
\hline Sinapic acid & NA & NA & \\
\hline Caffeate & 0.0325 & 0.899 & \\
\hline Sinapyl alcohol & NA & NA & \\
\hline p-Coumaryl alcohol & NA & NA & \\
\hline Caffeyl alcohol & NA & NA & \\
\hline Caffeyl aldehyde & NA & NA & \\
\hline Sinapinal dehyde & 0.0057 & 5.2929 & Up-regulated \\
\hline L-Phenylalanine & 0.0073 & 1.5573 & Up-regulated \\
\hline Coniferyl alcohol & 0.0072 & 20.4520 & Up-regulated \\
\hline Ferulic acid & 0.03586 & 1.9201 & Up-regulated \\
\hline 4-Hydroxy-3-methoxycinnamaldehyde & 0.0001 & 17.3515 & Up-regulated \\
\hline Cinnamic acid & 0.0004 & 2.4017 & Up-regulated \\
\hline \multicolumn{4}{|c|}{ GL50/GL20 } \\
\hline p-Coumaric acid & 0.0386 & 0.7140 & Down-regulated \\
\hline p-Coumaraldehyde & NA & NA & \\
\hline Sinapic acid & NA & NA & \\
\hline Caffeate & 0.0339 & 0.7823 & Down-regulated \\
\hline Sinapyl alcohol & NA & NA & \\
\hline p-Coumaryl alcohol & NA & NA & \\
\hline Caffeyl alcohol & NA & NA & \\
\hline Caffeyl aldehyde & NA & NA & \\
\hline Sinapinal dehyde & 0.0157 & 0.7338 & Down-regulated \\
\hline L-Phenylalanine & 0.0014 & $\longrightarrow$ & \\
\hline Coniferyl alcohol & 0.0082 & - & \\
\hline Ferulic acid & 0.0254 & 0.7034 & Down-regulated \\
\hline 4-Hydroxy-3-methoxycinnamaldehyde & 0.0497 & $\longrightarrow$ & \\
\hline Cinnamic acid & 0.0145 & - & \\
\hline
\end{tabular}




\subsection{Expression of Genes Related to Monomer and Polymer Lignin Contents}

All of the genes related to monomer and polymer lignin synthesis were selected from the libraries to further analyze their expression after sucrose and IAA treatment. A total of eight genes involved in monomer lignin synthesis was identified, and the expression of these genes did not change in the CK1/C0, GL20/C0, and GL50/C0 libraries after sucrose treatment (Figure $4 \mathrm{a}$ ), which indicated that sucrose had no effect on the content of monomer lignin at the transcription level. Genes involved in polymer lignin synthesis were also identified with these concentrations of sucrose treatment. In fact, five genes were found to be expressed at the transcriptional level. The mRNA levels of four genes, including $N n L A C 4, N n L A C 7, N n L A C 11$, and NnLAC17, were increased, and one gene (NnLAC1), was decreased after $20 \mathrm{~g} / \mathrm{L}$ and $50 \mathrm{~g} / \mathrm{L}$ sucrose treatment (Figure $4 \mathrm{~b}$ ). For these altered genes, including $N n L A C 4, N n L A C 7$, and $N n L A C 11$, no remarkable different change in expression was observed between the CK1/CK0 libraries, GL20/C0 libraries, and GL50/C0 libraries. However NnLAC17 was shown to have a lower transcriptional level in GL20/C0 libraries than that of CK1/CK0 and GL50/C0 libraries (Figure 4b), which indicated that $20 \mathrm{~g} / \mathrm{L}$ sucrose decreased NnLAC17 expression. For treatments with $10 \mu \mathrm{M}$ and $30 \mu \mathrm{M}$ IAA, C4H (cinnamate 4-hydroxylase), CCR (cinnayl-CoA reductase), CAD (cinnamyl alcohol dehydrogenase), and $\mathrm{F} 5 \mathrm{H}$ (ferulate 5-hydroxylase) related to monomer lignin synthesis altered their expression, whereas PAL (phenylalanine ammonia lysate) and COMT (cinnamate-O-methyltrasferase) had no significant changes in the transcriptional level. $C C R$ and $C A D$ had an increased expression in the $\mathrm{A} 1 / \mathrm{C} 0$ and $\mathrm{C} 1 / \mathrm{C} 0$ libraries compared to the $\mathrm{B} 1 / \mathrm{C} 0$ library, and $F 5 H$ had a greater transcriptional level in the $\mathrm{C} 1 / \mathrm{C} 0$ libraries than in the $\mathrm{A} 1 / \mathrm{C} 0$ libraries and $\mathrm{B} 1 / \mathrm{C} 0$ libraries (Figure 4c). In addition, all of the genes relevant to polymer lignin synthesis were chosen from these libraries. We found that the expression of two genes (NnLAC4 and NnLAC17) involved in polymer lignin synthesis were identified, and $N n L A C 17$ was found to have an improved transcription level in the $\mathrm{C} 1 / \mathrm{C} 0$ libraries compared to the $\mathrm{A} 1 / \mathrm{C} 0$ libraries and B1/C0 libraries (Figure 4d).

\subsection{Cloning and Expression of NnLAC17}

NnLAC17 was cloned from the lotus seedlings and sequenced by Sangon Biotech (Shanghai, China) Co., Ltd. This gene had a full-length sequence of $1749 \mathrm{bp}$ and encoded 583 amino acid residues. The deduced protein of NnLAC17 showed an $84 \%, 84 \%, 83 \%$, and 85\% similarity with that of Vitis riparia (XP_034687366.1), Vitis vinifera (XP_002284473.1), Spatholobus suberectus (TKY66042.1), and Trema orientale (PON84167.1), respectively (Additional Figure 1). In addition, a phylogenetic analysis of $L A C$ s revealed that all $L A C s$ could be classified into seven groups, and most of the groups included several members, aside from one group, which included only one gene (NcLAC17). SiLAC17, CsLAC17, NnLAC17, PeLAC17, PtLAC 17, PdLAC17, and RcLAC17 were classified into a group. Among those, CsLAC17 and NnLAC17 were classified into one sub-group, which indicated that the $L A C 17$ of lotuses was closely related to that of cucumbers in the gene sequence (Figure 5a). 

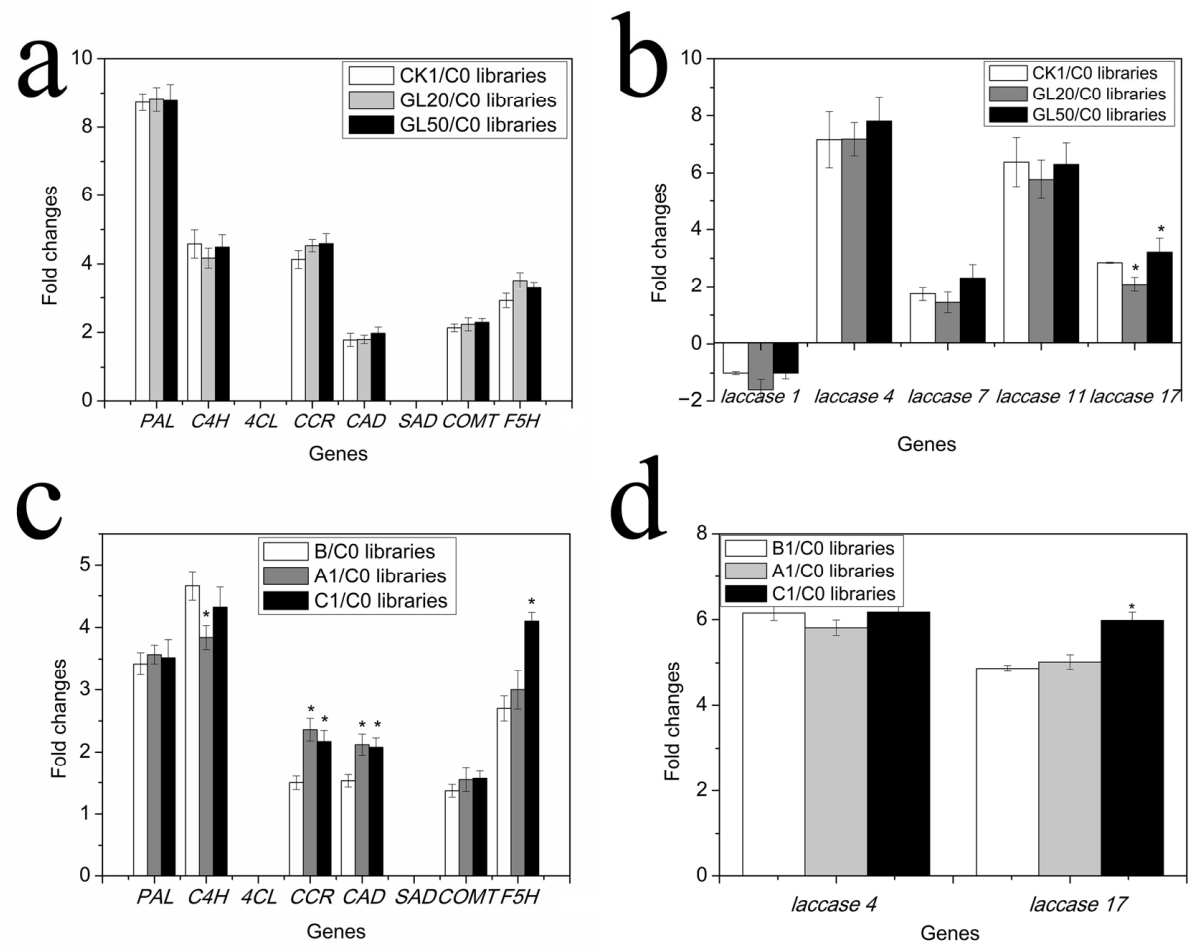

Figure 4. The expression of genes related to lignin synthesis during ARs formation in lotus seedlings. (a) The expression of genes related to monomer lignin synthesis in the GL20 and GL50 libraries. (b) The expression of genes related to polymer lignin synthesis in the C0, CK1, GL20, and GL50 libraries. (c) The expression of genes related to monomer lignin synthesis in the C0, A1, B, and C1 libraries. (d) The expression of genes related to polymer lignin synthesis in the C0, A1, B, and C1 libraries. ("*” represents significant difference at 0.05 level, $p<0.05$.)
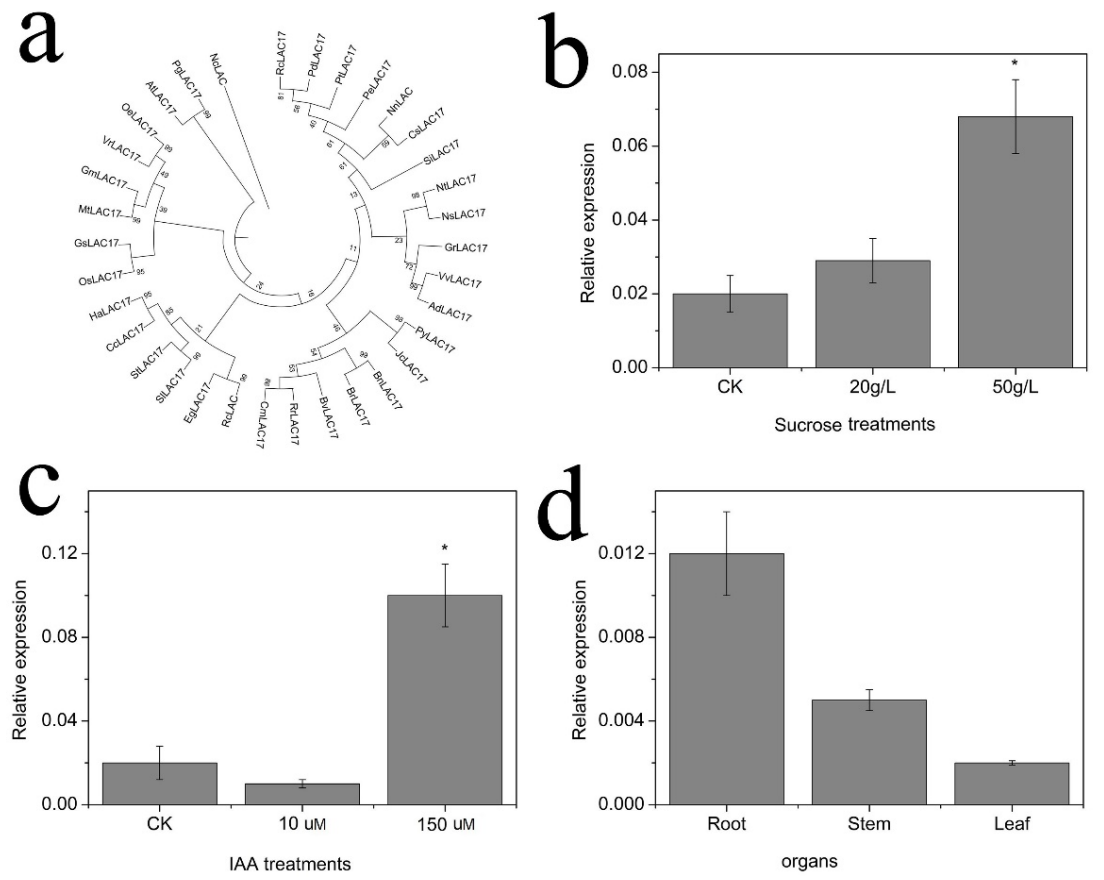

Figure 5. Cloning and expression analysis of NnLAC17 in lotus seedlings. (a) Analysis of the similarity between NnLAC17 and that of other species. (b) Relative expression of NnLAC17 in seedlings treated with $20 \mathrm{~g} / \mathrm{L}$ and $50 \mathrm{~g} / \mathrm{L}$ sucrose. (c) Relative expression of $N n L A C 17$ in seedlings treated with $10 \mu \mathrm{M}$ and $150 \mu$ M IAA. (d) Relative expression of NnLAC17 in different organs of lotuses. ("** represents significant different at 0.05 level, $p<0.05$.) 
Different concentrations of IAA and sucrose were applied to lotus seedlings, and the NnLAC17 expression was analyzed after two days of treatment. No significant difference in $N n L A C 17$ was observed at the transcription level in control plants and plants treated with $20 \mathrm{~g} / \mathrm{L}$ sucrose. However, $50 \mathrm{~g} / \mathrm{L}$ sucrose was found to remarkably enhance NnLAC17 gene expression (Figure $5 b$ ). The same phenomenon was also observed in seedlings treated with IAA. The seedlings treated with $150 \mu \mathrm{M}$ IAA had higher mRNA levels than the control plants and those treated with $10 \mu \mathrm{M}$ IAA (Figure 5c). Based on gene expression in different organs, a higher expression of NnLAC17 was observed in roots than in stems and leaves (Figure 5d).

\subsection{Functional Analysis of NnLAC17 in Transgenic Arabidopsis Thaliana}

sn1301: NnLAC17 was constructed and overexpressed in Arabidopsis plants by the control of a cauliflower mosaic virus 35S promoter to assess gene function. The "positive" plants were identified by hygromycin screening and the RT-PCR technique (Additional Figure 2). The T2 generation of transgenic plants was planted in the base material, and the root length and number were assessed with seedlings at 5-6 leaf age. The plant growth and length of roots in transgenic plants and non-transgenic plants had no significant difference (Figure 6a,b). Further analysis showed that an average of twenty-six roots in each plant was observed in non-transgenic plants at 5-6 leaf age, and approximately twenty roots were found in transgenic plants (Figure 6c), which indicated that the number of roots in transgenic plants decreased compared to non-transgenic plants. In addition, we observed that the content of polymer lignin was markedly increased in transgenic Arabidopsis plants after the overexpression of NnLAC17 (Figure 6d). Compared with non-transgenic plants, $N n L A C 17$ was found to participate in lignin synthesis, which was involved in the ARs development of lotus seedlings.

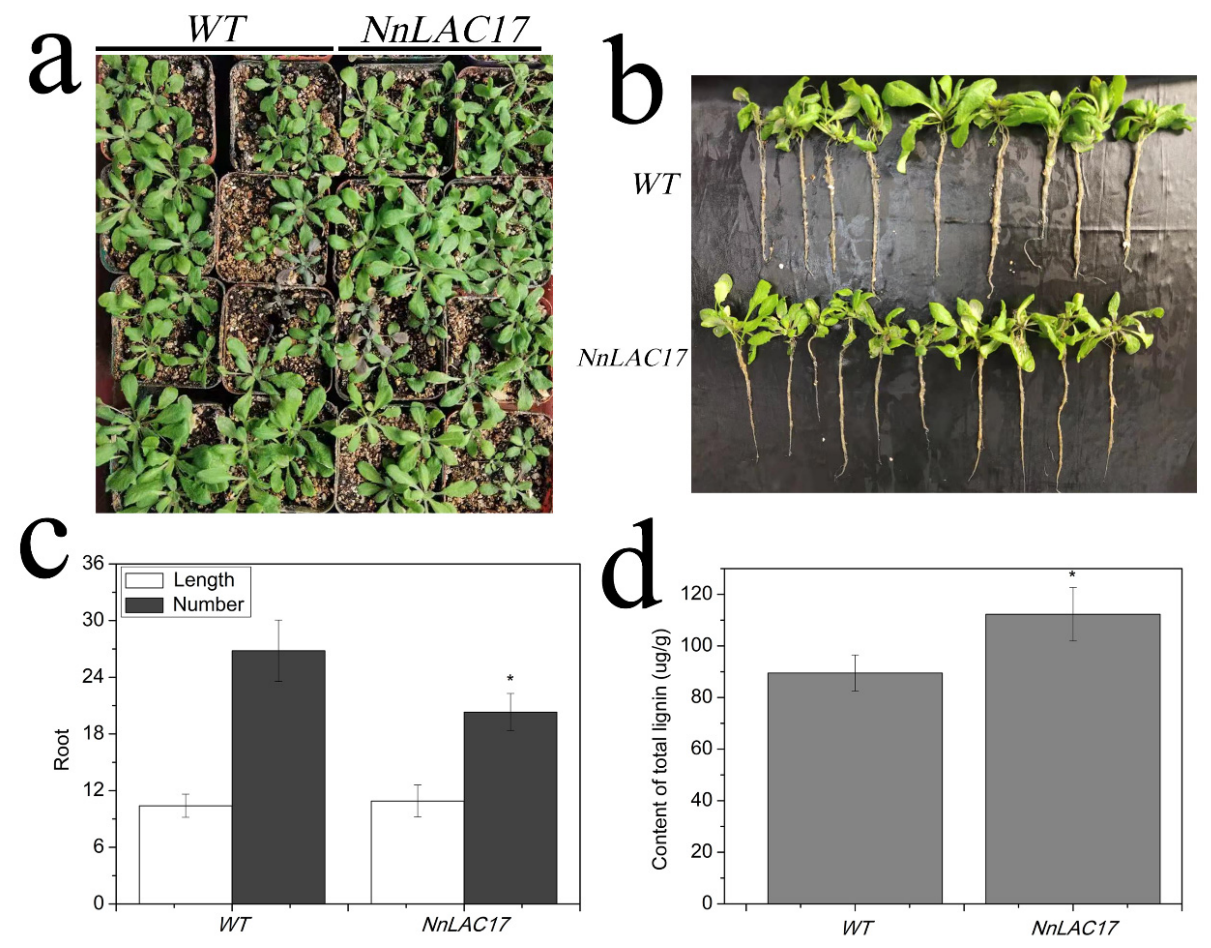

Figure 6. Functional analysis of NnLAC17 in transgenic Arabidopsis thaliana. (a) Phenotypic investigation of NnLAC17 transgenic plants and wild-type plants at 5-6 leaf age. (b) Comparative analysis of root length and number of transgenic plants and wild-type plants. (c) Determination of root length and number in NnLAC17 transgenic plants and wild-type plants (WT). (d) Investigation of polymer lignin in NnLAC17 transgenic plants and wild-type plants. ("** represents significant difference at 0.05 level, $p<0.05$; WT represents non-transgenic plants, and NnLAC17 represents transgenic plants with NnLAC17). 


\section{Discussion}

In this experiment, we observed that a high concentration $(50 \mathrm{~g} / \mathrm{L})$ of sucrose inhibited ARs formation, whereas a low concentration $(20 \mathrm{~g} / \mathrm{L})$ of sucrose promoted ARs development (Figure 1), suggesting that the sucrose signal is involved in ARs formation in the lotus seedlings. The developmental process of ARs in lotus seedlings, including the induction stage, which is the initial formation; the developmental stage of root primordium; and the expressed stage are found [6,30]. These stages are regulated by multiple factors [19,30-32]. IAA is involved in the early stages of root formation, and any incidence relevant to IAA synthesis and flux can affect root development [33-35]. Cheng et al. (2020) reported that the exogenous application of low concentrations of IAA $(10 \mu \mathrm{M})$ increases the ARs number, and further analysis reveals an IAA-regulating role at the induction stage and developmental stages in lotus seedlings [32]. Another important regulator of ARs development is sucrose, which has already been found in the plant kingdom. The effect of sucrose occurs throughout the entire stage of ARs development [32]. However, the pathway regulated by sucrose has not been uncovered. Recently, an interaction between sucrose and auxin was found to occur in ARs formation in lotus seedlings [31], suggesting that sucrose and auxin may simultaneously regulate ARs development.

In this study, a microstructural observation of the development of ARs is carried out. Treatment with $50 \mathrm{~g} / \mathrm{L}$ sucrose results in deeper crystal violet staining in the ARs primordium than that observed at CK and the treatment with $20 \mathrm{~g} / \mathrm{L}$ sucrose (Figure 2). Such findings suggest that a high correlation may exist between ARs formation and lignin deposition. This phenomenon has also been identified in carrot taproots. Lignin accumulation decreases after the application of exogenous IBA, which results in an increase in root length [36]. Lignin metabolism originates from the phenylpropanoid pathway and participates in various biological processes during plant growth $[37,38]$. Lignin depletion causes plant dwarfism, which is derived from the disruption of cell wall formation [39]. The silencing of $\mathrm{C} 4 \mathrm{H}$ can markedly decrease the lignin content and directly result in seedling lethality and an obstacle to leaf development [40]. Lignin deposition is found during root development in sweet potato, suggesting that lignin metabolism is closely correlated with root formation [41]. Further experiment shows that the decreased expression of $\mathrm{CH} 4$ reduces the number of Arabidopsis lateral roots relative to AUX transport [42]. Lotus seedlings treated with $50 \mathrm{~g} / \mathrm{L}$ sucrose were found to have a higher lignin content than at $\mathrm{CK}$. In addition, there was a significant decrease in the lignin content following treatment with $20 \mathrm{~g} / \mathrm{L}$ sucrose (Figure 3), suggesting that sucrose affects ARs formation derived from the regulation of lignin metabolism. Lignin deposition is related to the age of the plant. Durkovic et al. (2011) reports that 3-year-old plants have higher concentrations of lignin than 1-year-old plants [43]. Further, callus cells in roots have a higher lignin content than meristem [44]. In summary, root development and lignin deposition have a negative correlation, and lignin accumulation negatively affects root development.

Lignin synthesis includes two steps: monomer lignin synthesis and polymer lignin synthesis, and many genes are involved in these processes $[45,46]$. These biological processes are affected by many factors, including plant hormones, light, stress, temperature, and nitrate [47-50]. For the synthesis of monomer lignin, $P A L, C 4 H, 4 C L$ (4-coumarate-CoA ligase), $C C R, C A D, S A D$ (sinapyl alcoholdehydrogenas), COMT, and F5H catalyze the conversion of phenylalanine into p-coumaryl alcohol, sinapyl alcohol, and coniferyl alcohol, resulting in the formation of monomer lignin with the help of POD (peroxidase) [23,45,51-55]. The decreased expression of PALs and $4 C L$ reduces lignin accumulation [23,56], and the increased expression of $P O D$ can significantly improve the lignin content in plants [57]. In this study, we found no difference in the expression of $P A L, C 4 H, 4 C L, C C R, C A D, S A D$, $C O M T$, and $F 5 H$ under various concentrations of sucrose (Figure 4). However, the contents of p-coumaric acid, caffeate, sinapinal aldehyde, and ferulic acid were markedly decreased in the GL50/GL20 libraries (Table 1), which indicated that more metabolites were used in the synthesis of polymer lignin after $50 \mathrm{mg} / \mathrm{L}$ sucrose treatment. A further analysis was carried out in libraries treated with different concentrations of sucrose and IAA, and all 
$N n L A C s$ were selected to monitor the changes in gene expression related to lignin synthesis. We found that only NnLAC17 showed the same expression tendency; thus, the involvement of NnLAC17 in polymer lignin synthesis might be the main factor resulting in different lignin contents in lotus seedlings responding to various concentrations of sucrose and IAA.

LACs (Laccases) play an important role in the polymerization of lignin, which is involved in cell wall formation. In addition, the polymer distribution of lignin is regulated by LACs in gymnosperm compression wood [58]. Recently, LACs have been found to be involved in various abiotic stress responses in plants [49]. The overexpression of LAC2P can improve water transport, which leads to enhanced plant drought adaptation [59]. $\mathrm{H}_{2} \mathrm{O}_{2}$ (hydrogen peroxide) is reported to be an important signaling molecule. In fact, the exogenous application of $\mathrm{H}_{2} \mathrm{O}_{2}$ promotes AR formation in mung bean seedlings, whereas the expression of Laccase7, which is related to lignin synthesis, is found to be significantly reduced [60], suggesting that the formation of ARs and lignin content are opposing processes. Our data further revealed that increased lignin affected the root development in transgenic plants of Arabidopsis thaliana after the overexpression of a lotus gene, NnLAC17 (Figure 6). Such a finding also indicated that NnLAC17 might be an important gene regulating AR formation in lotuses by improving the lignin content.

Aside from its physiological role in plant growth, lignin also showed great commercial value. In fact, lignin has already been explored and utilized in the food industry, and is now considered as a valuable and renewable material for future food produce [61,62].

Zhang et al. (2013) have reported that lignin not only acts as a dietary fiber, but that it can also promote the activity of $\alpha$-amylase, which directly leads to a decrease in the $\alpha$-helical content, and improves the content of the polarity around tryptophan residues and protein granules [63]. A similar pheromone was also found, where lignin can also interact with wheat gluten to make protein soluble through the activity of aromatic hydroxyl antiradicals [64]. In lotuses, some kinds of organs, such as the lotus seed, leaf, and belt, have already been utilized to produce health foods, drinks, and even medicine (some value is derived from lignin) [32]. In this study, we found that the overexpression of NnLAC17 can improve the content of the transgenic Arabidopsis plant (Figure 6). Therefore, improving the lignin content by genetic engineering means that it is a probable available pathway to make food more nutritious and healthier in lotuses in the future.

\section{Materials and Methods}

\subsection{Plant Growth}

The lotus seed species, Taikong36, was selected for all experiments in this study. The seeds used in this study were derived from the open field of Yangzhou University. In spring (usually in April), the lotus was planted in the field for germination with moist soil. After the petiole broke through the soil surface, the water depth was maintained at 5-10 cm; the deeper water $(20-40 \mathrm{~cm})$ was required for the development of the plant and the available temperature was maintained between 20 and $30^{\circ} \mathrm{C}$ during the entire growth season. The application of fertilizer and pest control was carried out in the same manner employed in the conventional management of the field. The seeds were harvested in November and placed in a container at normal temperature.

\subsection{The Role of Sucrose in ARs Formation}

The seed coat of lotus was punched to enable the uptake of available water (for approximately three days) and placed at $26{ }^{\circ} \mathrm{C}$ for approximately two days under dark conditions. Fifty germinated seedlings from each treatment were selected and placed into $0 \mathrm{~g} / \mathrm{L}, 20 \mathrm{~g} / \mathrm{L}$, and $50 \mathrm{~g} / \mathrm{L}$ sucrose solutions for two days. The germination rates and numbers were counted on day 4 after transfer into water for $2 \mathrm{~d}$. At the same time, the shoot tips $(0.5 \mathrm{~cm})$ of lotus were sterilized with $75 \%$ ethanol for $20 \mathrm{~s}$, and then transferred into sodium hypochlorite (10\%) for $20 \mathrm{~min}$. All sterilized shoot tips were firstly cultured on the MS culture medium (MS $+30 \mathrm{~g}$ sucrose $+0.1 \% \mathrm{NaOH}+7 \mathrm{~g} / \mathrm{L}$ agar $+0.5 \mathrm{mg} / \mathrm{L}$ KT (kinetin) + $0.1 \mathrm{mg} / \mathrm{L}$ NAA (naphthalic acetic acid)) for approximately 30 days, and 
then were transferred to medium containing (MS $+0 \%, 20 \%$, or $50 \%$ sucrose $+0.1 \% \mathrm{NaOH}$ $+7 \mathrm{~g} / \mathrm{L}$ agar $+0.5 \mathrm{mg} / \mathrm{L} \mathrm{KT}+0.1 \mathrm{mg} / \mathrm{L} \mathrm{NAA})$ to continue cultivation for approximately 40 day, and the adventitious roots were counted. The temperature was $26^{\circ} \mathrm{C}$ with $12 \mathrm{~h}$ light and $12 \mathrm{~h}$ dark-light cycle. All statistical data were expressed as the mean $\pm \mathrm{SE}$ of three repetitions of experiments. The SPSS software ver. 14.0 (SPSS Inc., Chicago, IL, USA) was used for statistical analyses.

\subsection{Observation of the Paraffin Sections}

Seed treatment before germination and germination condition was the same as above. The treated seedlings with 20 and $50 \mathrm{mg} / \mathrm{L}$ sucrose were selected, and the hypocotyls of seedlings at $0,2,4$, and 6 days after treatment were cut into small pieces of $2.5 \mathrm{~mm} \times 2.5 \mathrm{~mm} \times 2 \mathrm{~mm}$ (length, width, and height), and then placed in a container filled with FAA fixing fluid (solution amount was 20-fold that of samples).

The container with fixed samples was produced in a vacuum state using a syringe for $5 \mathrm{~s}$. The lid of the container was opened for gas exchange after five min.

This process was repeated in triplicate. The container was transferred to a clean bench at normal temperature for $24 \mathrm{~h}$. Thereafter, 50\%, 70\%, 85\%, 95\%, and 100\% ethanol were applied to dehydrate the samples for approximately 25-30 $\mathrm{min}$. After dehydration with ethanol, the samples were treated with a mixed solution (one-half volume of ethanol and one-half volume of xylene and pure xylene) for approximately 25-30 min. Paraffin debris was prepared and thawed on an electric stove and then poured into the container with the samples for $24 \mathrm{~h}$. The tissues embedded in paraffin were cut into small blocks, and $10 \mu \mathrm{m}$ of wax tape was prepared using a slicer. The wax tapes were placed on a glass slide, and then, respectively, transferred into pure xylene, mixed solution (one-half volume of pure xylene and one-half volume of absolute ethanol), and absolute ethanol for $10 \mathrm{~min}$. The slide was dried at room temperature, and $2-3$ drops of $0.75 \%$ crystal violet solution were placed on the samples for $5 \mathrm{~min}$. The samples were washed with distilled water and then observed using an optical microscope.

\subsection{Determination of Monomer Lignin and Polymer Lignin Contents}

The hypocotyls of lotus seedlings treated with $20 \mathrm{mg} / \mathrm{L}$ and $50 \mathrm{mg} / \mathrm{L}$ for two days were used as materials to determine the monomer lignin and polymer lignin contents (CK0: 0 day of treatment; CK1: three days without treatment; GL50: three days with $50 \mathrm{~g} / \mathrm{L}$ sucrose treatment; GL20: three days with $20 \mathrm{~g} / \mathrm{L}$ sucrose treatment). For monomer lignin analysis, ten milligrams of dried sample were added to a mixture (2.5\% boron trifluoride, $10 \%$ ethanethiol, $87.5 \%$ dioxane) for $4 \mathrm{~h}$ in a metal bath followed by $300 \mu \mathrm{L}$ of $0.4 \mathrm{~m}$ sodium bicarbonate. The mixture was vibrated, and $2 \mathrm{~mL}$ water and $0.3 \mathrm{~mL}$ ethyl acetate were added. The mixture was centrifuged at 14,000 rpm for $10 \mathrm{~min}$ at normal temperature, and the supernatant was retrieved. The supernatant was dried with nitrogen, and $150 \mu \mathrm{L}$ pyridine (including an internal standard) and $50 \mu \mathrm{L}$ trimethylsilane were allowed to react at $60{ }^{\circ} \mathrm{C}$ for $1 \mathrm{~h}$. The mixture was centrifuged at $10,000 \mathrm{rpm}$ for $10 \mathrm{~min}$ at normal temperature, and the supernatant was retrieved for lignin identification. The lignin content was determined using a GC-MS instrument (7820A-5977B) from Agilent Technologies Inc. (Palo Alto, CA, USA). The conditions for chromatography (mass spectrometry) and quantitative analysis lignin were based on a previous protocol [65].

For polymer lignin analysis, $50 \mathrm{mg}$ of lotus seedlings dry powder was added into $1 \mathrm{~mL}$ of $70 \%$ ethanol with thorough vortex, and then centrifuged. The supernatant was discarded, and $1 \mathrm{~mL}$ of chloroform/methanol $(1: 1 \mathrm{v} / \mathrm{v})$ solution was added. After centrifuge, the supernatant was also discarded. A total of $1 \mathrm{~mL}$ acetone was added to wash precipitant, and then vacuumed for drying. A total of $1.5 \mathrm{~mL}$ sodium acetate buffer $(0.1 \mathrm{M}, \mathrm{Ph} 5.0)$ was put into tube with precipitant, and then heated at $80^{\circ} \mathrm{C}$ for $20 \mathrm{~min}$. Ten microliters of sodium azide $(0.01 \%)$ amylase and pullulanase were added and incubated overnight at $37^{\circ} \mathrm{C}$. The reaction was terminated by heating at $100{ }^{\circ} \mathrm{C}$ condition, and the supernatant was discarded by centrifugation at room temperature. Precipitation was cleaned by adding 
$\mathrm{H}_{2} \mathrm{O}$, and then $1 \mathrm{~mL}$ acetone was added. The mixture was vacuumed for dry acetone, and $1 \mathrm{mg}$ precipitate was chosen to be dissolved by $100 \mu \mathrm{L}$ acetyl bromide $(25 \%)$ solution under $50{ }^{\circ} \mathrm{C}$ for $3 \mathrm{~h}$. Then, $400 \mu \mathrm{L}$ sodium hydroxide $(2 \mathrm{M})$ and $70 \mu \mathrm{L}$ hydroxylamine hydrochloride $(0.5 \mathrm{M})$ were added and thoroughly mixed. The volume of mixture was fixed to $2 \mathrm{~mL}$ with acetic acid, and $200 \mu \mathrm{L}$ supernatant was used to measure absorbance value at $280 \mathrm{~nm}$ by multifunctional microplate reader (1510-04201, Biotek, Winooski, VT, USA). Polymer lignin content was counted using following formula:

$$
\text { Lignin content }=\frac{\text { ABS }}{\text { Coeff } \times 0.539 \mathrm{~cm}} \times \frac{2 \mathrm{~mL}}{\text { Weight }} \times 100 \%
$$

ABS: light absorption value; Coeff: absorption coefficient.

In addition, the roots of six-leaf stage seedlings of transgenic Arabidopsis plants and none of the transgenic plants were collected for polymer lignin identification. The material treatment and identification method was the same as that mentioned above.

\subsection{Metabolite Analysis of Lignin during ARs Formation}

The hypocotyls of control lotus seedlings and seedlings treated with $20 \mathrm{~g} / \mathrm{L}$ and $50 \mathrm{~g} / \mathrm{L}$ for two days were selected for metabolites analysis. All freeze-dried hypocotyls were crushed using a mixer mill (MM 400, Retsch, Shanghai, China) with a zirconia bead for $1.5 \mathrm{~min}$ at $30 \mathrm{~Hz}$. Powder $(100 \mathrm{mg})$ was weighed and extracted for approximately $12 \mathrm{~h}$ at $4{ }^{\circ} \mathrm{C}$ with $1.2 \mathrm{~mL} 70 \%$ aqueous methanol. Following centrifugation at $10,000 \times g$ for $10 \mathrm{~min}$ at normal temperature, the extracts were absorbed (CNWBOND Carbon-GCB SPE Cartridge, 250 mg, 3 mL; ANPEL, Shanghai, China, www.anpel.com.cn/cnw (accessed on 22 April 2021)) and filtered (SCAA-104, $0.22 \mu \mathrm{m}$ pore size; ANPEL, Shanghai, China, http: / / www.anpel.com.cn/ (accessed on: 16 May 2021)) before UPLC-MS/MS analysis.

\subsection{UPLC (Ultra Performance Liquid Chromatography) Conditions}

The sample extracts were analyzed using a UPLC-ESI-MS/MS system (UPLC, Shim-pack UFLC SHIMADZUCBM 30A system, www.shimadzu.com.cn/ (accessed on: 23 May 2020); MS, Applied Biosystems 6500 QTRAP, www.appliedbiosystems.com.cn (accessed on 23 May 2020). The analytical conditions were as follows: column, Waters ACQUITYUPLCHSST3C18 $(1.8 \mu \mathrm{m}, 2.1 \mathrm{~mm} \times 100 \mathrm{~mm})$; and mobile phase, solvent A- pure water with $0.04 \%$ acetic acid and solvent B- acetonitrile with $0.04 \%$ acetic acid. Sample measurements were performed with an Agilent program that employed the starting conditions of $95 \%$ A and $5 \% \mathrm{~B}$. Within $10 \mathrm{~min}$, a linear gradient to $5 \% \mathrm{~A}$ and $95 \% \mathrm{~B}$ was employed, and a composition of $5 \% \mathrm{~A}$ and $95 \%$ B was maintained for 1 min. Subsequently, a composition of $95 \%$ A and $5.0 \%$ B was employed for $0.10 \mathrm{~min}$ and retained for $2.9 \mathrm{~min}$. The column oven temperature was set to $40{ }^{\circ} \mathrm{C}$, and the injection volume was $2 \mu \mathrm{L}$. The effluent was alternatively connected to an ESI-triple quadrupole-linear ion trap (QTRAP)-MS.

\subsection{ESI-QTRAP-MS/MS}

LIT and triple quadrupole (QQQ) scans were acquired on a triple quadrupole-linear ion trap mass spectrometer (Q TRAP), API 6500 Q TRAP UPLC/MS/MS system, equipped with an ESI Turbo Ion Spray interface, operating in positive and negative ion mode and controlled by Analyst 1.6.3 software (AB Sciex). The ESI source parameters were as follows: ion source, turbo spray; source temperature, $550{ }^{\circ} \mathrm{C}$; ion spray voltage (IS), $5500 \mathrm{~V}$ (positive ion mode)/ $-4500 \mathrm{~V}$ (negative ion mode); ion source gas I (GSI), gas II (GSII), and curtain gas (CUR) 50, 60, and 30.0 psi, respectively; and collision gas (CAD), high. Instrument tuning and mass calibration were performed with 10 and $100 \mu \mathrm{mol} / \mathrm{L}$ polypropylene glycol solutions in the QQQ and LIT modes, respectively. QQQ scans were acquired as MRM experiments with a collision gas (nitrogen) set at 5 psi. DP and CE for individual MRM transitions were performed with further optimization of DP and CE. A specific set of MRM transitions was monitored for each period, according to the metabolites eluted within this period. 


\subsection{RNA-seq Analysis of the Differentially Expressed Genes}

For the analysis of differentially expressed genes, all genes related to monomer and polymer lignin synthesis were selected and their expression profiles were monitored after treatment with IAA $(10 \mu \mathrm{M}$ and $150 \mu \mathrm{M})$ and sucrose $(20 \mathrm{~g} / \mathrm{L}$ and $50 \mathrm{~g} / \mathrm{L})$ during AR formation. In the previous study, four libraries treated with $10 \mu \mathrm{M}$ and $150 \mu \mathrm{M}$ of IAA (CK library: germinating seeds without treatment; A library, initial AR stages: 2-3 days of seedlings with $10 \mu \mathrm{M}$ IAA treatment; B library: 2-3 days of seedlings without IAA treatment; C library: 2-3 days of seedlings with $150 \mu \mathrm{M}$ IAA treatment) and sucrose (C0 library: the samples were collected at day 0; CK1, GL20, and GL50 libraries: the samples were collected at day 1 after treatment with 0,20 , and $50 \mathrm{~g} / \mathrm{L}$ sucrose respectively) were constructed, and the data have been published by Cheng et al. (2018a) and Cheng et al. (2020a), respectively [19,32]. These data include the samples of the CK library (germinating seeds without treatment), A library (initial AR stages: 2-3 days of seedlings with $10 \mu \mathrm{M}$ IAA treatment), B library (2-3 days of seedlings without IAA treatment), and C library (2-3 days of seedlings with $150 \mu \mathrm{M}$ IAA treatment). Genes related to the synthesis of lignin, including monomer and polymer lignin, were selected from above libraries for further analysis.

\subsection{Cloning and Sequence Analysis of NnLAC17}

The sequence of NnLAC17 was derived from the NCBI database according to the gene expression profile under sucrose treatment. Lotus RNA was extracted from the hypocotyls of three old seedlings using a plant RNA (Ribonucleic Acid) extract mix (Tiangen, Beijing, China). DNase was applied to eliminate residual DNA (Deoxyribonucleicacid) before cDNA synthesis, which was performed according to the protocol of the mix kit (Promega, Madison, WI, USA). A total of $20 \mu \mathrm{L}$ of PCR (Polymerase Chain Reaction) reaction mixture, which included $2.5 \mu \mathrm{L}$ dNTP, $2 \mu \mathrm{L}$ forward and reverse primers, $2.5 \mu \mathrm{L} \mathrm{MgCl}_{2}, 0.5 \mu \mathrm{L}$

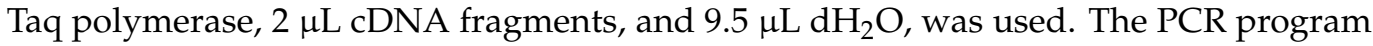
included 35 cycles: $94{ }^{\circ} \mathrm{C}$ for $1 \mathrm{~min}, 94^{\circ} \mathrm{C}$ for $1 \mathrm{~min}, 60^{\circ} \mathrm{C}$ for $1 \mathrm{~min}, 72^{\circ} \mathrm{C}$ for $1 \mathrm{~min}$, and $72{ }^{\circ} \mathrm{C}$ for $10 \mathrm{~min}$. Forward primer: 5-ATGGGTTCCTTTGTTCTTCC-3; reverse primer: 5-AGGCGGTAGTTTCTGATTTG-3. The plasma of DNA plasmid was sent to Sangon Biotechnology Co., Ltd. (Shanghai, China) for sequencing. For sequence analysis, five LACs, including lotus, vitis riparia, vitis vinifera, spatholobus suberectus, and trema orientale, was used for alignment analysis by DNAman software. In addition, thirty-four $L A C$ s from different plants were selected, and MEGA-X software was used for phylogenetic tree construction.

\subsection{Expression Analysis of NnLAC17 in Lotus}

The expression profile of NnLAC17 was determined using qRT-PCR (Quantitative Reverse Transcription PCR). The hypocotyls of seedlings treated with sucrose (0, 20, and $50 \mathrm{~g} / \mathrm{L})$ and IAA $(0,10$, and $150 \mu \mathrm{M})$ were selected at 4 days after being transferred into water for transcriptional level analysis. For the expression of NnLAC17 in different organs, the leaf, stem, and hypocotyls of seedlings at 6 days (cultivation in water) were selected to monitor expression changes. Total plant RNA was derived from these samples, and DNase was used to eliminate residual DNA. The primer was designed based on the NnLAC17 sequence using the primer 5.0 software. Forward primer was 5-GGGTTCCTTTGTTCTTCCA-3, and reverse primer was 5-GCCAGTGCAAGGTGATATT-3. NnActin was used as the internal standard. The NnActin forward primer was 5'-ACGCGTATGAAGTCAGTTGT-3' and reverse primer was 5'-TTTATGGGGATCAGCTGGT-3'. A $25 \mu \mathrm{L}$ reaction mixture was prepared, which contained 12.5 $\mu \mathrm{L}$ SYBR Premix Ex Taq II (Tli RNaseH Plus) $(2 \times), 1 \mu \mathrm{L}$ of each of the forward and reverse primers, $2 \mu \mathrm{L} \mathrm{cDNA}$, and $8.5 \mu \mathrm{L} \mathrm{dH}_{2} \mathrm{O}$. The PCR program consisted of $30 \mathrm{~s}$ at $94^{\circ} \mathrm{C}$, followed by 40 cycles of $95^{\circ} \mathrm{C}$ for $5 \mathrm{~s}$ and $60 \mathrm{~s}$ at $60^{\circ}$. Three biological replicates were carried out in this experiment. For data analysis, the $2^{-\Delta \Delta \mathrm{Ct}}$ method was used to identify NnLAC17 expression. The $\triangle \mathrm{Ct}$ value was obtained according to the $\mathrm{Ct}$ (target) and $\mathrm{Ct}$ (actin) values in treated plants $(\Delta \mathrm{Ct}$ (target)) and control $(\Delta \mathrm{Ct}$ 
(normal), and the $\Delta \Delta \mathrm{Ct}$ value was calculated according to the data of $\Delta \mathrm{Ct}$ (target) and $\Delta \mathrm{Ct}$ (normal). Based on the $\Delta \Delta \mathrm{Ct}$ value, the $2^{-\Delta \Delta \mathrm{Ct}}$ value was determined.

\subsection{Vector Construction}

NnLAC17 was cloned and inserted into a clone vector (pGEM-T). pGEM-T was transformed into Escherichia coli to expand reproduction. After identification, positive clones were cultured in LB culture medium. The plasmid was extracted from bacterial fluid and digested with BamHI and KpnI enzymes. Thereafter, the digestion product (sequence of $N n L A C 17)$ was inserted into the plant transformation vector with a CaMV 35S promoter. The pSN1301:: NnLAC17 plasmid was inserted into the Agrobacterium tumefaciens strain, GV3101. The floral dip method [66] was employed to transform NnLAC17 into the wildtype Arabidopsis plant. The transformed Arabidopsis was cultured in the glasshouse, and seeds were harvested after approximately three months of growth. Sterilized seeds of the T0 generation were tiled on MS medium containing $20 \mu \mathrm{g} \cdot \mathrm{g}^{-1}$ hygromycin B to select 'positive' plants. The temperature of the chamber was $22^{\circ} \mathrm{C}$ with $12 \mathrm{~h}$ light and $12 \mathrm{~h}$ dark-light cycle. In addition, RT-PCR (Reverse Transcription PCR) method was applied for further identification, and the primers were: forward primer was 5-GGGTTCCTTTGTTCTTCCA-3, and reverse primer was 5-GCCAGTGCAAGGTGATATT-3. Reaction mixture and program process was the same as gene expression. Base on the information of data, three lines of positive plants were selected for further study.

\subsection{Identification of NnLAC17 Function in Arabidopsis Plants}

The seeds of transgene (T2 generation) and wild-type plants were cultured in pots, and seven-leaf-old transgenic seedlings and wild-type plants were selected for functional analysis. Further, the seeds of the transgene (T2 generation) and wild-type seeds were sterilized with $75 \%$ alcohol for $20 \mathrm{~s}$ and transformed into sodium hypochlorite (30\%) for $20 \mathrm{~min}$. The sterilized seeds were sown on the medium, and root number and length was counted at six-leaf age of seedlings. For statistical analysis, all data are presented as the mean \pm SE of triplicate independent treatments, with approximately 10 seedlings per experiment, and approximately thirty seedlings being used for three biological replicates. The SPSS software ver. 14.0 (SPSS Inc., Chicago, IL, USA) was used for data analysis.

\subsection{Statistical Analysis}

Statistical analyses were performed using the SPSS software ver. 14.0 (SPSS Inc., Chicago, IL, USA). Approximately twenty plants in each experiment were used for statistical analysis. The data were recorded as the means \pm SE of three experiments, and the differences at $p<0.05$ were accepted as the level of significance.

\section{Conclusions}

In this study, we found that lignin synthesis was strictly regulated by sucrose according to the change in monomer and polymer lignin content. In addition, the microstructural observation and intermediate metabolites of lignin confirmed that lignin synthesis is involved in the sucrose signal transduction pathway in the seedlings of lotuses. Based on the above result, genes involved in lignin synthesis (monomer and polymer lignin) were identified in the libraries treated with different concentrations of sucrose. NnLAC17 was selected and considered as an important gene in lignin synthesis, according to gene expression, in responding to sucrose and IAA treatment. Further experiments, including spatiotemporal expression and transgenic Arabidopsis thaliana, uncovered that lignin synthesis, which is affected by NnLAC17, is a key factor involved in the ARs formation of lotus seeding.

Author Contributions: L.C. and S.L. conceived and designed the experiments. C.Z. performed the experiments. M.Z. analyzed the data. Y.H. performed the experiments and analyzed the data. L.C. and S.L. wrote the text file. All authors have read and agreed to the published version of the manuscript. 
Funding: This work was supported by the cooperation project of Yangzhou and Yangzhou University (YZ2020187), and the modern agricultural development project of Jiangsu Province (2020-SJ-003YD17). All the funders listed in this manuscript have no role in the design and performance of all experiments, analysis of data, and in the writing of the manuscript.

Institutional Review Board Statement: Not applicable.

Informed Consent Statement: Not applicable.

Data Availability Statement: The materials of all of the experiments were supported by aquatic vegetable Labof Yangzhou University. The collection of seeds complied with local and national guidelines and permissions of seeds were obtained. The detailed data derived from sucrose treatment have been deposited in the NCBI database (Bioproject number). All of the raw tags derived from IAA treatment were deposited in the National Center for Biotechnology Information (BioProject ID: PRJNA398315; accession number: SRR5944803-SRR5944814).

Acknowledgments: We extend our thanks to members of the BIG for their cooperation in obtaining the data during the AR formation of the lotus by the RNA-seq technique.

Conflicts of Interest: The authors declare no conflict of interest.

\section{References}

1. Shen-Miller, J. Sacred lotus, the long-living fruits of China Antique. Seed Sci. Res. 2002, 12, 131-143.

2. Ming, R.; Van Buren, R.; Liu, Y.; Yang, M.; Han, Y.; Li, L. Genome of the Long living sacred lotus (Nelumbo nucifera Gaertn.). Genome Biol. 2013, 14, R41. [CrossRef]

3. Cheng, L.B.; Liu, H.Y.; Jiang, R.Z.; Li, S.Y. A Proteomics analysis of adventitious root formation after leaf removal in lotus (Nelumbo nucifera Gaertn.). ZNC 2018, 73, 375-389. [CrossRef]

4. Kevers, C.; Hausman, J.F.; Faivre-Rampant, O.; Evers, D.; Gaspar, T. Hormonal control of adventitious rooting: Progress and questions. J. Appl. Bot. Angew. Bot. 1997, 71, 71-79.

5. Li, S.; Xue, L.; Xu, S.; Feng, H.; An, L. Mediators, genes and signaling in adventitious rooting. Bot. Rev. 2009, 75, 230-247. [CrossRef]

6. Rasmussen, A.; Hosseini, S.A.; Hajirezaei, M.R.; Druege, U.; Geelen, D. Adventitious rooting declines with the vegetative to reproductive switch and involves a changed auxin homeostasis. J. Exp. Bot. 2015, 66, 1437-1452. [CrossRef]

7. Teale, W.D.; Paponov, I.A.; Palme, K. Auxin in action: Signaling, transport and the control of plant growth and development. Nat. Rev. Mol. Cell. Biol. 2006, 7, 847-859.

8. Calvo-Polanco, M.; Senorans, J.; Zwiazek, J.J. Role of adventitious roots in water relations of tamarack (Larix laricina) seedlings exposed to flood. BMC Plant Biol. 2012, 12, 99. [CrossRef]

9. Rovere, D.; Fattorini, L.; Angeli, S.D.; Veloccia, A.; Falasca, G.; Altamura, M.M. Auxin and cytokinin control formation of the quiescent centre in the adventitious root apex of Arabidopsis. Ann. Bot. 2013, 112, 1395-1407.

10. Fukaki, H.; Tasaka, M. Hormone interactions during lateral root formation. Plant Mol. Biol. 2009, 69, 437-449.

11. Mensuali-Sodi, A.; Panizza, M.; Tognoni, F. Endogenous ethylene requirement for adventitious root induction and growth in tomato cotyledons and lavandin microcuttings in vitro. Plant Growth Regul. 1995, 17, 205-212. [CrossRef]

12. Pan, R.; Wang, J.; Tian, X. Influence of ethylene on adventitious root formation in mung bean hypocotyl cuttings. J. Plant Growth Regul. 2002, 36, 135-139.

13. Steffens, B.; Wang, J.; Sauter, M. Interactions between ethylene, gibberellin and abscisic acid regulate emergence and growth rate of adventitious roots in deepwater rice. Planta 2006, 223, 604-612. [CrossRef]

14. Riov, J.; Yang, S. Ethylene and auxin-ethylene interaction in adventitious root formation in mung bean (Vigna radiata) cuttings. J. Plant Growth Regul. 1989, 8, 131-141. [CrossRef]

15. Negi, S.; Sukumar, P.; Liu, X.; Cohen, J.D.; Muday, G.K. Genetic dissection of the role of ethylene in regulating auxin-dependent lateral and adventitious root formation in tomato. Plant J. 2010, 61, 3-15. [CrossRef]

16. Visser, E.; Cohen, J.D.; Barendse, G.; Blom, C.; Voesenek, L. An ethylene-mediated increase in sensitivity to auxin induces adventitious root formation in flooded rumex palustrissm. Plant Physiol. 1996, 112, 1687-1692. [CrossRef]

17. Cano-Delgado, A.I.; Metzlaff, K.; Bevan, M.W. The eli1 mutation reveals a link between cell expansion and secondary cell wall formation in Arabidopsis thaliana. Development 2000, 127, 3395-3405.

18. Takahashi, F.; Sato-Nara, K.; Kobayashi, K.; Suzuki, M.; Suzuki, H. Sugar-induced adventitious roots in Arabidopsis seedlings. J. Plant Res. 2003, 116, 83-91.

19. Cheng, L.B.; Zhao, M.R.; Hu, Z.B.; Liu, H.Y.; Li, S.Y. Comparative transcriptome analysis revealed the cooperative regulation of sucrose and IAA on adventitious root formation in lotus (Nelumbo nucifera Gaertn). BMC Genomics 2020, $21,653$.

20. Barros, J.; Serk, H.; Granlund, I.; Pesquet, E. The cell biology of lignification in higher plants. Ann. Bot. 2015, 115, 1053-1074. [CrossRef] 
21. Shioya, T.; Akiyama, T.; Yokoyama, T.; Matsumot, Y. Formation rate of benzyl cation intermediate from p-Hydroxyphenyl, guaiacyl, or syringyl nucleus in acidolysis of lignin. J. Wood Chem. Tech. 2017, 37, 75-86. [CrossRef]

22. Cho, H.; Chang, C.; Huang, L.; Tsai, J.; Liu, Z. Indole-3-butyric acid suppresses the activity of peroxidase while inducing adventitious roots in Cinnamomum kanehirae. Bot. Study 2011, 52, 153-160.

23. Quiroga, M.; Guerrero, C.; Botella, M.A.; Barcelo, A.; Amaya, I.; Medina, M.I.; Alonso, F.J.; de Forchetti, S.M.; Tigier, H.; Valpuesta, V. A tomato peroxidase involved in the synthesis of lignin and suberin. Plant Physiol. 2000, 122, 1119-1127. [CrossRef]

24. Chou, C.H.; Huang, Y.C.; Liu, Z. Peroxidase genes differentially respond to auxin during the formation of adventitious roots in soybean hypocotyl. Plant Growth Regul. 2010, 60, 151-161. [CrossRef]

25. Syros, T.; Yupsanis, T.; Zafiriadis, H.; Economou1, A. Activity and isoforms of peroxidases, lignin and anatomy, during adventitious rooting in cuttings of Ebenus cretica L. J. Plant Physiol. 2004, 161, 69-77. [CrossRef]

26. Singh, V.; Sergeeva, L.; Ligterink, W.; Aloni, R.; Zemach, H.; Doron-Faigenboim, A.; Yang, J.; Zhang, P.; Shabtai, S.; Firon, N. Gibberellin promotes sweetpotato root vascular lignification and reduces storage-root formation. Front. Plant Sci. 2019, 10, 1320. [CrossRef] [PubMed]

27. Ponniah, S.K.; Thimmapuram, J.; Bhide, K.; Kalavacharla, V.; Manoharan, M. Comparative analysis of the root transcription of cultivated sweetpotato (Ipomoea batatas [L.] Lam) and its wild ancestor (Ipomoea trifida [Kunth] G. Don). BMC Plant Biol. 2017, 17, 9. [CrossRef]

28. Li, S.; Shi, R.; Leng, Y.; Zhou, Y. Transcriptomic analysis reveals the gene expression profile that specifically responds to IBA during adventitious rooting in mung bean seedlings. BMC Genom. 2016, 17, 43. [CrossRef]

29. Piacentinia, D.; Ronzana, M.; Fattorinia, L.; DellaRoverea, F.; Massimib, L.; Altamuraa, M.M. Nitric oxide alleviates cadmium-but not arsenic-induced damages in rice roots. Plant Physiol. Biochem. 2020, 151, 729-742. [CrossRef]

30. Cheng, L.B.; Han, Y.Y.; Liu, H.Y.; Jiang, R.Z.; Li, S.Y. Transcriptomic analysis reveals ethylene's regulation involved in adventitious roots formation in lotus (Nelumbo nucifera Gaertn.). Acta Physiol. Plant. 2019, 41, 97.

31. Cheng, L.B.; Han, Y.Y.; Zhao, M.R.; Li, S.Y. Gene expression profiling reveals the effects of light on adventitious root formation in lotus seedlings (Nelumbo nucifera Gaertn.). BMC Genomics 2020, 21, 707.

32. Cheng, L.B.; Jiang, R.Z.; Yang, J.J.; Xu, X.Y.; Zeng, H.T.; Li, S.Y. Transcriptome profiling reveals an IAA-regulated response to adventitious root formation in lotus seedling. Z. Naturforsch. 2018, 73, 229-240.

33. Hobbie, L.; Estelle, E. The axr4 auxin-resistant mutants of Arabidopsis thaliana define a gene important for root gravitropism and lateral root initiation. Plant J. 1995, 7, 211-220. [CrossRef] [PubMed]

34. Casimiro, I.; Marchant, A.; Bhalerao, R.P.; Beeckman, T.; Dhooge, S.; Swarup, R.; Graham, N.; Inzé, D.; Sandberg, G.; Casero, P.J.; et al. Auxin transport promotes Arabidopsis lateral root nitiation. Plant Cell. 2001, 13, 843-852. [CrossRef] [PubMed]

35. Marchant, A.; Bhalerao, R.; Casimiro, I.; Eklöf, J.; Casero, P.J.; Bennet, M.; Sandberg, G. AUX1 promotes lateral root formation by facilitating indole-3-acetic acid distribution between sink and source tissues in the Arabidopsis seedling. Plant Cell. 2002, 14, 589-597. [CrossRef]

36. Khadr, A.; Wang, G.; Wang, Y.; Zhang, R.; Wang, X.; Xu, Z.; Tian, Y.-S.; Xiong, A.-S. Effects of auxin (indole-3-butyric acid) on growth characteristics, lignification, and expression profiles of genes involved in lignin biosynthesis in carrot taproot. Peer $\mathbf{2 0 2 0}$ 8, e10492. [CrossRef]

37. Brunetti, C.; Fini, A.; Sebastiani, F.; Gori, A. Modulation of phytohormone signaling: A primary function of flavonoids in plant environment interactions. Front. Plant Sci. 2018, 9, 1042. [CrossRef]

38. Vanholme, R.; De Meester, B.; Ralph, J.; Boerjan, W. Lignin biosynthesis and its integration into metabolism. Curr. Opin. Biotech. 2019, 56, 230-239. [CrossRef]

39. Dolan, W.L.; Dilkes, B.P.; Stout, J.M.; Bonawitz, N.D.; Chapple, C. Mediato omplex subunits MED2, MED5, MED16, and MED23 genetically interact in the regulation of phenylpropanoid biosynthesis. Plant Cell. 2017, 29, 3269-3285. [CrossRef]

40. Schilmiller, A.L.; Stout, J.; Weng, J.K.; Humphreys, J.; Ruegger, M.O.; Chapple, C. Mutations in the cinnamate 4-hydroxylase gene impact metabolism, growth and development in Arabidopsis. Plant J. 2009, 60, 771-782. [CrossRef]

41. Singh, V.; Zemach, H.; Shabtai, S.; Aloni, R.; Yang, J.; Zhang, P.; Sergeeva, L.; Ligterink, W.; Firon, N. Proximal and distal parts of sweet potato adventitious roots display differences in root architecture, lignin, and starch metabolism and their developmental fates. Front. Plant Sci. 2021, 11, 609923. [CrossRef] [PubMed]

42. Houari, I.E.; Beirs, C.V.; Arents, H.E.; Han, H.B.; Chanoca, A.; Opdenacker, D.; Pollier, J.; Storme, V.; Steenackers, W.; Quareshy, M.; et al. Seedling developmental defects upon blocking CINNAMATE-4-HYDROXYLASE are caused by perturbations in auxin transport. New Phytol. 2021, 230, 2275-2291. [CrossRef] [PubMed]

43. Durkovic, J.; Kanuchova, A.; Kacık, F.; Solar, R.; Lengyelova, A. Genotype- and age-dependent patterns of lignin and cellulose in regenerants derived from 80-year-old trees of black mulberry (Morus nigra L.). Plant Cell Tissue Organ. Cult. 2011, 108, 359-370. [CrossRef]

44. Eliyahu, A.; Duman, Z.; Sherf, S.; Genin, O.; Cinnamon, Y.; Abu-Abied, M.; Weinstain, R.; Dag, A.; Sadot, E. Vegetative propagation of elite Eucalyptus clones as food source for honeybees (Apis mellifera); adventitious roots versus callus formation. Israel J. Plant Sci. 2020, 67, 83-97. [CrossRef]

45. Wang, Y.; Teng, R.; Wang, W.; Wang, Y.; Shen, W.; Zhuang, J. Identification of genes revealed differential expression profiles and lignin accumulation during leaf and stem development in tea plant [Camellia sinensis (L.) O. Kuntze]. Protoplasma 2019, 256, 359-370. [CrossRef] 
46. Liu, Q.; Luo, L.; Zheng, L. Lignins: Biosynthesis and biological functions in plants. Int. J. Mol. Sci. 2018, 19, 335. [CrossRef]

47. Han, M.; Yang, N.; Wan, Q.; Teng, R.; Duan, A.; Wang, Y.; Zhuang, J. Exogenous melatonin positively regulates lignin biosynthesis in Camellia sinensis. Int. J. Biol. Macromol. 2021, 179, 485-499. [CrossRef]

48. Zhang, X.; Lu, M.; Ludlow, R.A.; Ma, W.; An, H. Transcriptome analysis reveals candidate genes for dietary fiber metabolism in Rosa roxburghii fruit grown under different light intensities. Hort. Environ. Biol. 2021, 62, 751-764. [CrossRef]

49. Lu, C.; Yang, T.; Zhang, Y.; Miao, X.; Jin, C.; Xu, X. Genome-wide analyses and expression patterns under abiotic stress of LAC gene family in pear (Pyrus bretschneideri). Plant Biotech. Rep. 2021, 15, 403-416. [CrossRef]

50. Shao, C.; Qiu, C.; Qian, Y.; Liu, G. Nitrate deficiency decreased photosynthesis and oxidation-reduction processes, but increased cellular, transport, lignin biosynthesis and flavonoid metabolism revealed by RNA-Seq in Oryza sativa leaves. PLoS ONE 2020, 15, e0235975. [CrossRef]

51. Wang, G.; Huang, Y.; Zhang, X.; Xu, Z.; Wang, F.; Xiong, A. Transcriptome-based identification of genes revealed differential expression profiles and lignin accumulation during root development in cultivated and wild carrots. Plant Cell Rep. 2016, 35, 1743-1755. [CrossRef] [PubMed]

52. Ye, Z.; Zhong, R.; Morrison, W.H.; Himmelsbach, D.S. Caffeoyl coenzyme A O-methyltransferase and lignin biosynthesis. Phytochemistry 2001, 57, 1177-1185. [CrossRef]

53. Duan, A.; Feng, K.; Wang, G.; Liu, J.; Xu, Z.; Xiong, A. Elevated gibberellin enhances lignin accumulation in celery (Apium graveolens L.) leaves. Protoplasma 2019, 256, 777-788. [CrossRef]

54. Hoffmann, L.; Maury, S.; Martz, F.; Geoffroy, P.; Legrand, M. Purification, cloning, and properties of an acyltransferase controlling shikimate and quinate ester intermediate in phenylpropanoid metabolism. J. Biol. Chem. 2003, 278, 95-103. [CrossRef] [PubMed]

55. Huang, J.; Gu, M.; Lai, Z.; Fan, B.; Shi, K.; Zhou, Y.; Yu, J.-Q.; Chen, Z. Functional analysis of the Arabidopsis PAL gene family in plant growth, development, and response to environmental stress. Plant Physiol. 2018, 153, 1526-1538. [CrossRef] [PubMed]

56. Gui, J.; Shen, J.; Li, L. Functional characterization of evolutionarily divergent 4-coumarate: Coenzyme a ligases in rice. Plant Physiol. 2011, 157, 574-586. [CrossRef]

57. Kim, Y.H.; Kim, C.Y.; Song, W.K.; Park, D.S.; Kwon, S.Y.; Lee, H.S.; Bang, J.-W.; Kwak, S.-S. Overexpression of sweetpotato swpa4 peroxidase results in increased hydrogen peroxide production and enhances stress tolerance in tobacco. Planta 2008, 227, 867-881. [CrossRef]

58. Hiraide, H.; Tobimatsu, Y.; Yoshinaga, A.; Lam, P.Y.; Kobayashi, M.; Matsushita, Y.; Fukushima, K.; Takabe, K. Localised laccase activity modulates distribution of lignin polymers in gymnosperm compression wood. New Phytol. 2021, 230, $2186-2199$. [CrossRef]

59. Niu, Z.; Li, G.; Hu, H.; Lv, J.; Zheng, Q.; Liu, J.; Wan, D. A gene that underwent adaptive evolution, LAC2 (LACCASE), in Populus euphratica improves drought tolerance by improving water transport capacity. Hort. Res. 2021, 8, 88. [CrossRef]

60. Li, S.; Xue, L.; Xu, S.; Fent, H.; An, H. IBA-induced changes in antioxidant enzymes during adventitious rooting in mung bean seedlings: The role of $\mathrm{H}_{2} \mathrm{O}_{2}$. Environ. Exp. Bot. 2009, 66, 442-450. [CrossRef]

61. Abaturov, B.D.; Kolesnikov, M.P.; Likhnova, O.P.; Petrishchev, B.I.; Nikonova, O.A. Use of plant forage lignin and silica as digestibility indicators for quantitative estimation of food consumption by free-ranging saigas. Zoologicheskii Zhurnal 1997, 76, 106-113.

62. Tao, J.M.; Li, S.; Ye, F.Y.; Zhou, Y.; Lei, L.; Zhao, G.H. Lignin-An underutilized, renewable and valuable material for food industry. Crit. Rev. Food Sci. Nutr. 2020, 60, 2011-2033. [CrossRef] [PubMed]

63. Zhang, J.; Cui, J.H.; Yin, T.T.; Sun, L.Z.; Li, G.X. Activated effect of lignin on $\alpha$-amylase. Food Chem. 2013, 141, 2229-2237. [CrossRef]

64. Kaewtatip, K.; Menut, P.; Auvergne, R.; Tanrattanakul, V.; Morel, M.H.; Guilbert, S. Interactions of kraft lignin and wheat gluten during biomaterial processing: Evidence for the role of phenolic groups. J. Agric. Food Chem. 2010, 58, 4185-4192. [CrossRef] [PubMed]

65. Teng, R.M.; Wang, Y.X.; Li, H.; Lin, S.J.; Liu, H.; Zhang, J. Effects of shading on lignin biosynthesis in the leaf of tea plant (Camellia sinensis (L.) O. Kuntze). Mol. Genet. Genom. 2021, 296, 165-177. [CrossRef]

66. Clough, S.J.; Bent, A.F. Floral dip: A simplified method for Agrobacterium-mediated transformation of Arabidopsis thaliana. Plant J. 1998, 16, 735-743. [CrossRef] 